\title{
Aplikasi Monitoring Jaringan Berbasis Mobile Web dengan Sistem Notifikasi Berbasis SMS Gateway
}

\author{
(Studi Kasus : Sekolah Islam Al-Azhar Bumi Serpong Damai)
}

\author{
Andi Amrurrahman Maula, Hendra Bayu Suseno, Andrew Fiade \\ Program Studi Teknik Informatika \\ Fakultas Sains dan Teknologi \\ Universitas Islam Negeri Syarif Hidayatullah Jakarta
}

\begin{abstract}
Abstrak-Kegiatan monitoring jaringan sangat penting dilakukan secara rutin agar jaringan dapat dipastikan selalu dalam kondisi baik dan tersedia bagi penggunanya. Administrator jaringan adalah orang yang bertanggung jawab dalam mengelola jaringan komputer, salah satu tugas dari seorang administrator jaringan adalah monitoring jaringan. Di tempat penulis melakukan penelitian, monitoring jaringan masih dilakukan secara manual dan administrator jaringan tidak dapat selalu mengawasi jaringan yang dikelolanya akibat banyaknya pekerjaan lain yang harus dilakukan. Untuk itu pada penelitian ini dibuat suatu tools yang dapat digunakan dari mana saja berupa aplikasi berbasis mobile web yang mampu melakukan monitoring terhadap jaringan. Kegiatan monitoring yang dilakukan aplikasi meliputi pemeriksaan koneksi jaringan, status ketersediaan port, pemakaian сри dan memory, pencatatan kondisi jaringan, pemantauan URL yang diakses client, reboot host, restart service, dan memberikan notifikasi SMS tentang keadaan jaringan menggunakan SMS gateway. Metode pengembangan sistem yang digunakan pada penelitian ini adalah Rapid Application Development yang memiliki 3 fase yaitu: perencanaan syaratsyarat, workshop design, dan implementasi (Kendall \& Kendall, 2008). Pengujian aplikasi dilakukan dengan metode blackbox dengan hasil pengujian menunjukkan bahwa fungsi tiap modul/fitur aplikasi ini telah berfungsi dengan baik. Dengan fitur notifikasi melalui SMS dan interface yang dirancang untuk mobile web, aplikasi ini mempermudah administrator jaringan mengawasi jaringan yang dikelolanya dari mana saja melalui perangkat apapun dengan browser yang sudah mendukung javascript dan jquery.
\end{abstract}

Kata Kunci-sms gateway; monitoring jaringan; mobile web

\section{PENDAHULUAN}

Pemanfaatan teknologi informasi dan jaringan komputer sebagai media komunikasi data hingga saat ini semakin meningkat. Kebutuhan atas penggunaan bersama sumber daya (resources) yang ada dalam jaringan baik software maupun hardware telah mengakibatkan timbulnya berbagai pengembangan teknologi jaringan itu sendiri.

Teknologi informasi dan komunikasi yang banyak digunakan saat ini menggunakan sistem jaringan komputer sebagai media transformasi informasi maupun datanya, semakin besar sebuah perusahaan atau instansi yang menggunakan jaringan komputer maka semakin kompleks pula sistem jaringan pada perusahaan atau instansi tersebut, dan dibutuhkan sebuah penanganan yang baik agar sistem dapat berjalan dengan optimal.

Network administrator adalah orang yang bertanggung jawab dalam mengelola jaringan komputer, ada banyak tugas pokok dan fungsi dari seorang network administrator atau admin jaringan, salah satunya adalah pemantauan atau monitoring jaringan. Kegiatan monitoring jaringan sangat penting dilakukan secara rutin agar jaringan dapat dipastikan selalu dalam kondisi baik dan tersedia bagi pengguna sistem.

Berdasarkan wawancara dengan pihak terkait di tempat penulis melakukan penelitian yaitu Sekolah Islam Al-Azhar BSD, Kota Tangerang Selatan, Banten, administrator jaringan masih menggunakan cara sederhana dalam memeriksa koneksi jaringannya yaitu dengan melakukan ping ke host-host yang terhubung dalam jaringan, hal tersebut memang memungkinkan untuk dapat dilakukan bila host yang terhubung dan diawasinya hanya sedikit, namun apabila host yang terhubung ada dalam jumlah besar maka cara tersebut akan menghabiskan waktu serta tidak efisien untuk dilakukan. Selain itu administrator jaringan di Al-Azhar BSD memiliki pekerjaan yang sangat banyak dikarenakan IT Al-Azhar BSD juga merupakan bagian dari divisi humas sehingga administrator tidak dapat selalu melakukan monitoring secara rutin dan terjadwal. Berangkat dari latar belakang tersebut dan mengingat pentingnya kegiatan monitoring jaringan, maka penulis berinisiatif membuat suatu aplikasi monitoring jaringan berbasis mobile web yang dilengkapi sistem notifikasi keadaan jaringan menggunakan SMS untuk membantu administrator jaringan Sekolah Islam Al-Azhar BSD melakukan monitoring jaringan yang dikelolanya secara mudah dan dapat dilakukan dari mana saja melalui suatu perangkat mobile.

\section{METODE PENELITIAN}

2.1 Metode Pengumpulan Data

A. Wawancara

Pengumpulan data dan informasi dengan cara mengadakan tanya jawab dengan pihak terkait. 
B. Observasi

Pengumpulan data dan informasi dengan meninjau langsung dan mengamati secara langsung kegiatan yang terjadi di lapangan untuk memperoleh informasi yang diperlukan.

C. Pustaka

Pengumpulan data dan informasi dengan cara membaca referensi yang dapat dijadikan landasan dasar dalam penelitian ini.

2.2 Metode Pengembangan Sistem (Rapid Application Development)

A. Perencanaan Syarat-syarat

Menganalisa dan mengidentifikasi tujuan-tujuan aplikasi dan syarat-syarat informasi yang dihasilkan dari tujuan tersebut. Orientasi dari fase ini adalah menyelsaikan masalah-masalah yang timbul pada saat menganalisa aplikasi yang akan dibangun.

B. Workshop Design

Merancang dan memperbaiki rancangan yang telah dibuat. Selama workshop design RAD, pengguna merespon prototipe sistem yang ada dan menganalisa, memperbaiki modul-modul yang dirancang menggunakan perangkat lunak.

C. Implementasi

Analis bekerja secara intens untuk merancang aspek-aspek bisnis dan non teknis dari aspek bisnis. Segera setelah aspek-aspek ini disetujui dan sistem dibangun dan disharing, sistem kemudian diujicoba.

\section{Tools Penelitian}

1.1 Perangkat Lunak (Software)

1. Notepad++ 5.8.7 untuk Text Editor.

2. Framework Codeigniter 1.7.3.

3. Framework jQuery Mobile 1.2.1.

4. SqStat 1.20 sebagai library untuk membaca active request pada Squid Proxy

5. PHPSecLib 0.3.1 sebagai library untuk melakukan restart service dan reboot device melalui antarmuka web.

6. XAMPP/LAMPP 1.7.1 (mencakup Apache, MySQL, PHP, dan PhpMyAdmin).

7. Gammu 1.32 untuk SMS Gateway.

8. PHPSysInfo 3.1.3 untuk melakukan monitoring sumber daya host pada jaringan.

\subsection{Perangkat Keras (Hardware)}

Tabel 3.1 Perangkat Keras Penelitian

\begin{tabular}{|l|l|l|l|}
\multicolumn{4}{c}{ Tabel 3.1 Perangkat Keras Penelitian } \\
\hline Hardware & Processor & RAM & Sistem Operasi \\
\hline PC & $\begin{array}{l}\text { AMD Dual } \\
\text { Core E450 } \\
1,65 \mathrm{GHz}\end{array}$ & $\begin{array}{l}\text { 4GB } \\
\text { DDR3 }\end{array}$ & $\begin{array}{l}\text { Windows 7 Ultimate \& } \\
\text { Ubuntu 11.10 }\end{array}$ \\
\hline $\begin{array}{l}\text { Komputer } \\
\text { Server }\end{array}$ & $\begin{array}{l}\text { AMD Opteron } \\
\text { Quad Core } \\
2,35 \mathrm{GHz}\end{array}$ & $\begin{array}{l}8 \mathrm{~GB} \\
\text { DDR3 }\end{array}$ & $\begin{array}{l}\text { Ubuntu Server 12.04 } \\
\text { LTS }\end{array}$ \\
\hline $\begin{array}{l}\text { Smartphone } \\
\text { Android }\end{array}$ & $\begin{array}{l}\text { Snapdragon } \\
1,4 \mathrm{Ghz}\end{array}$ & $512 \mathrm{MB}$ & $\begin{array}{l}\text { Android 2.3.5 } \\
\text { Gingerbread }\end{array}$ \\
\hline $\begin{array}{l}\text { Smartphone } \\
\text { Blackberry }\end{array}$ & $806 \mathrm{Mhz}$ & $512 \mathrm{MB}$ & Blackberry OS 7 \\
\hline Wavecom & - & - & - \\
\hline
\end{tabular}

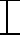

\section{PERENCANAAN SYARAT-SYARAT}

\subsection{Analisa Sistem Berjalan dan Permasalahan}

Tabel 4.1 Identifikasi Permasalahan

\begin{tabular}{|c|c|c|}
\hline Objek Analisa & Sistem Berjalan & Permasalahan \\
\hline Pemeriksaan koneksi & $\begin{array}{l}\text { Dilakukan secara } \\
\text { manual dengan ping } \\
\text { ke masing-masing } \\
\text { host satu per satu } \\
\text { melalui command line } \\
\text { interface }\end{array}$ & $\begin{array}{l}\text { Memerlukan banyak } \\
\text { waktu jika dilakukan } \\
\text { pada banyak host dan } \\
\text { menyulitkan } \\
\text { penelusuran masalah } \\
\text { pada jaringan }\end{array}$ \\
\hline $\begin{array}{l}\text { Pencatatan data } \\
\text { device }\end{array}$ & $\begin{array}{l}\text { Belum menggunakan } \\
\text { database dan } \\
\text { dilakukan dengan } \\
\text { media kertas }\end{array}$ & $\begin{array}{l}\text { Data tidak teratur . } \\
\text { Rentan rusak dan } \\
\text { hilang bila tidak } \\
\text { disimpan dengan baik }\end{array}$ \\
\hline $\begin{array}{l}\text { Pencatatan kondisi } \\
\text { dan keaktifan } \\
\text { perangkat jaringan }\end{array}$ & Belum ada & $\begin{array}{l}\text { Tidak adanya } \\
\text { dokumentasi keadaan } \\
\text { jaringan }\end{array}$ \\
\hline Sistem notifikasi & Belum ada & $\begin{array}{l}\text { Jika admin jaringan } \\
\text { tidak melakukan } \\
\text { tracing error secara } \\
\text { manual atau tidak } \\
\text { adanya laporan, maka } \\
\text { administrator tidak } \\
\text { akan mengetahui ada } \\
\text { masalah pada jaringan }\end{array}$ \\
\hline $\begin{array}{l}\text { Pemantauan kondisi } \\
\text { perangkat pada } \\
\text { jaringan }\end{array}$ & $\begin{array}{l}\text { Melakukan remote } \\
\text { melalui port } \mathrm{SSH} \\
\text { mapun remote } \\
\text { desktop satu per satu } \\
\text { ke masing-masing } \\
\text { perangkat }\end{array}$ & $\begin{array}{l}\text { Sulit dilakukan pada } \\
\text { banyak perangkat. }\end{array}$ \\
\hline $\begin{array}{l}\text { Pemantauan request } \\
\text { URL yang dilakukan } \\
\text { client }\end{array}$ & $\begin{array}{l}\text { Dilakukan dengan } \\
\text { melihat log pada } \\
\text { proxy server }\end{array}$ & $\begin{array}{l}\text { Kurang praktis karena } \\
\text { diakses melalui } \\
\text { command line } \\
\text { interface }\end{array}$ \\
\hline
\end{tabular}

Setelah melakukan identifikasi permasalahan maka selanjutnya mengajukan sistem yang ditawarkan untuk mengatasi permasalahan-permasalahan tersebut.

Tabel 4.2 Sistem Yang Ditawarkan

\begin{tabular}{|l|l|l|}
\hline \multicolumn{1}{|c|}{ Objek Analisa } & \multicolumn{1}{|c|}{ Sistem Berjalan } & \multicolumn{1}{c|}{ Sistem Ditawarkan } \\
\hline $\begin{array}{l}\text { Pemeriksaan } \\
\text { koneksi }\end{array}$ & $\begin{array}{l}\text { Dilakukan secara manual } \\
\text { dengan ping ke masing- } \\
\text { masing } \text { host } \text { satu per satu } \\
\text { melalui command line } \\
\text { interface }\end{array}$ & $\begin{array}{l}\text { Pembuatan modul } \\
\text { pemeriksaan seluruh } \\
\text { host sekaligus secara } \\
\text { otomatis }\end{array}$ \\
\hline $\begin{array}{l}\text { Pencatatan data } \\
\text { device }\end{array}$ & $\begin{array}{l}\text { Belum menggunakan } \\
\text { database dan dilakukan } \\
\text { dengan media kertas }\end{array}$ & $\begin{array}{l}\text { Pembuatan modul } \\
\text { inventory perangkat } \\
\text { untuk menyimpan data } \\
\text { perangkat ke dalam } \\
\text { database }\end{array}$ \\
\hline
\end{tabular}




\begin{tabular}{|l|l|l|}
\hline $\begin{array}{l}\text { Pencatatan } \\
\text { kondisi dan } \\
\text { keaktifan } \\
\text { perangkat } \\
\text { jaringan }\end{array}$ & Belum ada & $\begin{array}{l}\text { Pembuatan modul } \\
\text { pencatatan otomatis } \\
\text { terhadap kondisi } \\
\text { perangkat jaringan }\end{array}$ \\
\hline $\begin{array}{l}\text { Sistem notifikasi } \\
\text { Belum ada }\end{array}$ & $\begin{array}{l}\text { Pembuatan sistem } \\
\text { notifikasi berbasis SMS } \\
\text { gateway yang } \\
\text { dapatmemberikan } \\
\text { notifikasi berkala } \\
\text { kepada administrator } \\
\text { jaringan Al-Azhar BSD }\end{array}$ \\
$\begin{array}{l}\text { pemantauan } \\
\text { perangkat pada } \\
\text { jaringan }\end{array}$ & $\begin{array}{l}\text { Melakukan remote } \\
\text { melalui port SSH mapun } \\
\text { remote desktop satu per } \\
\text { satu ke masing-masing } \\
\text { perangkat }\end{array}$ & $\begin{array}{l}\text { Pembuatan modul yang } \\
\text { memudahkan } \\
\text { pemantauan kondisi } \\
\text { banyak perangkat } \\
\text { jaringan }\end{array}$ \\
\hline $\begin{array}{l}\text { Pemantauan } \\
\text { request URL } \\
\text { client }\end{array}$ & $\begin{array}{l}\text { Dilakukan dengan melihat } \\
\text { log pada proxy server }\end{array}$ & $\begin{array}{l}\text { Menyertakan fitur } \\
\text { pemantauan request } \\
\text { dRL pada sistem yang } \\
\text { ditawarkan }\end{array}$ \\
\hline
\end{tabular}

2.2 Mengumpulkan Informasi Jaringan Sekolah Islam AlAzhar BSD

Setelah penulis melakukan analisa sistem berjalan dan sistem yang ditawarkan, penulis mengumpulkan informasiinformasi data jaringan yang diperlukan. Data yang penulis dapatkan adalah sebagai berikut:

1. Jumlah perangkat jaringan yang akan dimonitoring yaitu 6 unit server dan 6 router.

2. IP Address tiap perangkat jaringan.

3. Sistem operasi setiap perangkat jaringan

4. Topologi jarinagn Al-Azhar BSD, yaitu topologi star.

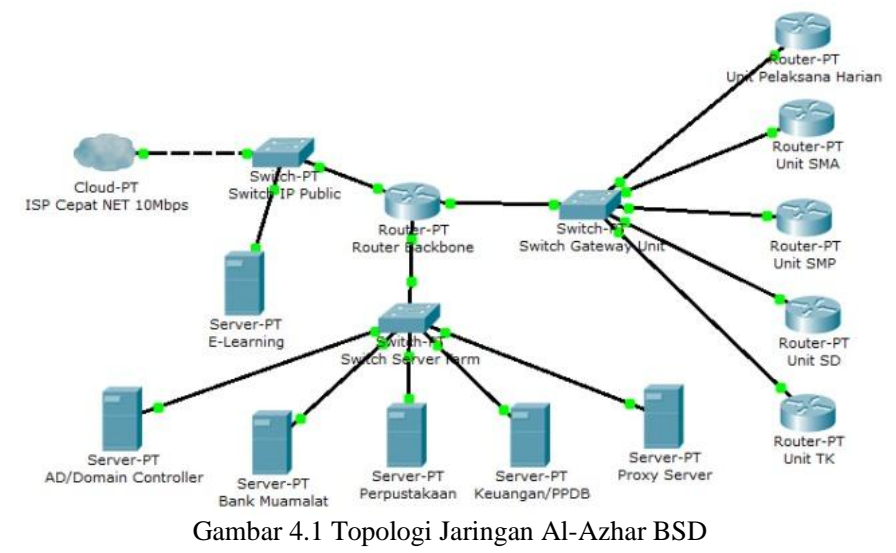

2.3 Menganalisa Aplikasi Sejenis Mengenai Monitoring Jaringan

Penulis melakukan analisa pada aplikasi Sistem Monitoring Jaringan Berbasis Web pada Pusdatin UIN Jakarta yang dibuat oleh Deni Lastiawan. Penulis mendapati bahwa aplikasi tersebut belum mempunyai sistem notifikasi baik melalui Email maupun SMS serta kurang optimal apabila diakses melalui mobile browser sehingga kurang efisien apabila ingin mengakses sistem dari mana saja.
Penulis juga melakukan studi literatur pada penelitian yang dilakukan oleh Abdul Gani yang berjudul Perancangan Monitoring Server Menggunakan Nagios Dengan Memanfaatkan Email. Pada penelitian ini sistem monitoring mengirimkan notifikasi kepada administrator jaringan melalui email yang bergantung kepada koneksi internet, apabila koneksi internet bermasalah maka notifikasi keadaan jaringan tidak dapat terkirim.

\subsection{Menentukan Aktor Dan Mengidentifikasi Fitur-fitur Aplikasi}

Identifikasi fitur-fitur aplikasi yang dilakukan yaitu mencakup tujuan-tujuan aplikasi atau sistem dan syarat-syarat informasi yang ditimbulkan dari tujuan-tujuan tersebut.

Aplikasi yang penulis rancang akan memiliki beberapa fitur/modul yaitu:

1. Menampilkan status host yang terhubung ke jaringan. Informasi yang ditampilkan meliputi:

a. Status ketersediaan host pada jaringan apakah online atau offline.

b. Status port HTTP (port 80), FTP (port 21), SMTP (port 25), SSH (port 22), Telnet (port 23), dan HTTPS (port 443).

c. Detail informasi mengenai host yang meliputi nama host, alamat IP, Mac Address, lokasi host, subnet, status pemakaian CPU, dan status pemakaian memory (RAM).

d. Catatan waktu perubahan kondisi pada host.

2. Menampilkan list active request yang melalui server proxy berbasis Squid.

3. Menampilkan catatan persentase uptime dari host yang terhubung ke jaringan.

4. Sistem inventaris perangkat jaringan.

5. Pengaturan notifikasi perubahan keadaan host pada jaringan melalui SMS.

6. Melakukan reboot device dan restart service secara remote.

7. Pengelolaan user dan hak aksesnya.

Setelah menentukan fitur-fitur aplikasi, penulis memisahkan tingkatan aktor pengguna aplikasi/sistem serta hak aksesnya dalam penggunaan fitur-fitur aplikasi. Aktor pengguna aplikasi yang penulis rancang dibagi ke dalam 3 tingkatan yakni:
1.Head Administrator
2.Administrator
3.Co-Administrator

Tabel 4.3 Tingkatan Pengguna dan Hak Aksesnya

\begin{tabular}{|l|l|l|l|}
\hline \multirow{2}{*}{ Modul } & \multicolumn{3}{c|}{ Tingkatan Pengguna } \\
\cline { 2 - 4 } & $\begin{array}{c}\text { Head Administra- } \\
\text { tor }\end{array}$ & $\begin{array}{c}\text { Administra- } \\
\text { tor }\end{array}$ & $\begin{array}{c}\text { Co- } \\
\text { Administr } \\
\text { ator }\end{array}$ \\
\hline Status Host & $\checkmark$ & $\checkmark$ & $\checkmark$ \\
\hline $\begin{array}{l}\text { Active } \\
\text { Request }\end{array}$ & $\checkmark$ & $\checkmark$ & $\checkmark$ \\
\hline Log Uptime & $\checkmark$ & $\checkmark$ & $\checkmark$ \\
\hline
\end{tabular}




\begin{tabular}{|l|l|l|l|}
\hline $\begin{array}{l}\text { Inventori } \\
\text { Perangkat }\end{array}$ & $\checkmark$ & $\checkmark$ & $\mathrm{X}$ \\
\hline $\begin{array}{l}\text { Pengaturan } \\
\text { Notifikasi } \\
\text { SMS }\end{array}$ & $\checkmark$ & $\checkmark$ & $\mathrm{X}$ \\
\hline $\begin{array}{l}\text { Pengelolaan } \\
\text { User dan } \\
\text { Hak Akses }\end{array}$ & $\checkmark$ & $\mathrm{X}$ & $\mathrm{X}$ \\
\hline
\end{tabular}

\section{WORKSHOP DESIGN}

\subsection{Pemodelan Aplikasi}

Pemodelan aplikasi dibuat menggunakan Unified Modeling Language (UML) yang terdiri dari use case diagram, activity diagram, sequence diagram, dan class diagram. Setelah membuat dan melakukan analisa pada use case, activity, dan sequence diagram, penulis membuat class diagram sebagai berikut:

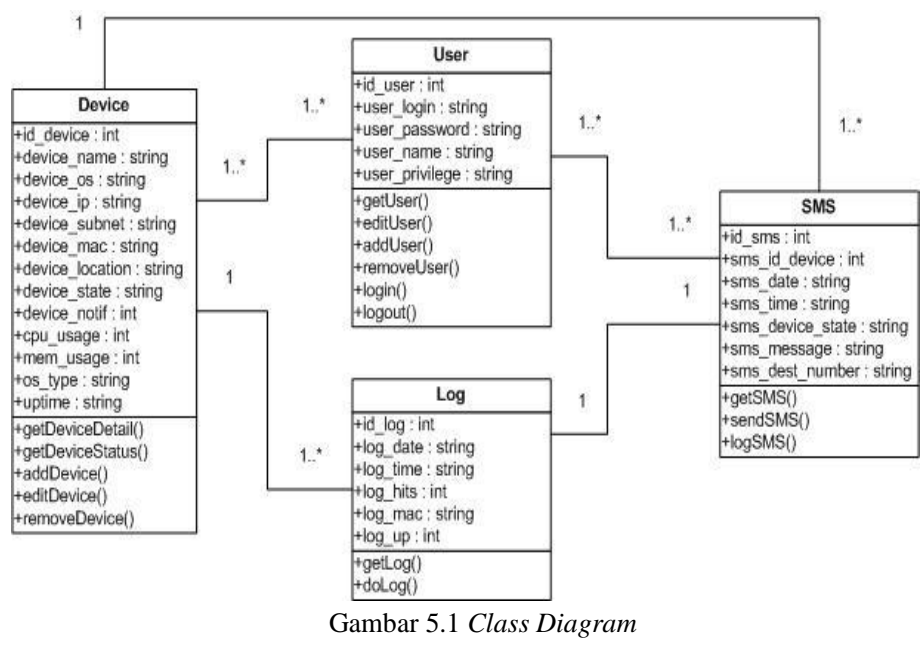

\subsection{Perencanaan User Interface}

Pada tahap ini, penulis melakukan perancangan user interface atau tampilan antarmuka pengguna dari aplikasi.

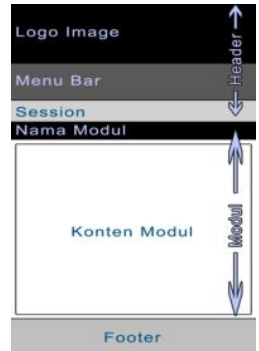

Gambar 5.1 Rancangan Tampilan Aplikasi

\subsection{Diagram Arsitektur Sistem}

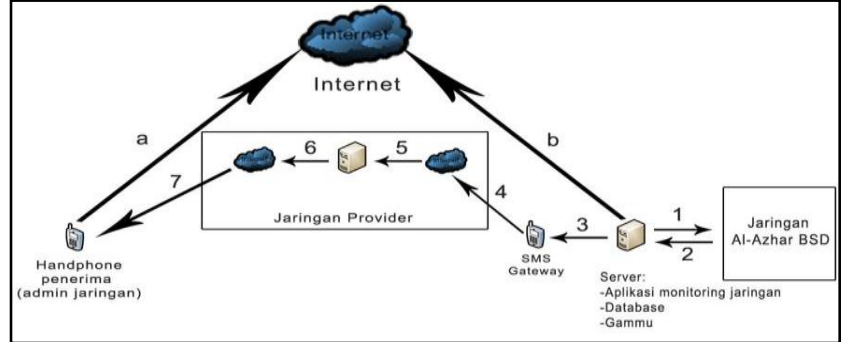

Gambar 5.2 Diagram Arsitektur Sistem

Penjelasan:

1. Aplikasi memonitoring jaringan Al-Azhar BSD secara otomatis dengan cronscript yang sudah dijadwalkan secara berkala.

2. Aplikasi pada server monitoring menerima input hasil dari kegiatan monitoring jaringan yang dilakukan secara berkala.

3. Aplikasi dengan memanfaatkan Gammu mengirimkan notifikasi mengenai keadaan jaringan hasil monitoring melalui SMS gateway.

4. SMS gateway mengiriman notifikasi SMS ke nomor tujuan (admin jaringan).

5. SMS yang terkirim melalui SMS gateway oleh provider selular di-store ke SMS center.

6. Setelah itu, SMS di-forward ke nomor tujuan oleh SMS center.

7. Administrator jaringan menerima notifikasi keadaan jaringan yang dikelolanya melalui SMS.

Pada gambar juga terdapat panah dari handphone penerima ke internet yang diberi label huruf a dan dari server aplikasi ke internet yang diberi label huruf b. Panah dengan label a menggambarkan administrator jaringan yang mengakses aplikasi monitoring pada server aplikasi melalui internet sedangkan panah dengan label $b$ menggambarkan server aplikasi yang terhubung ke internet dan dapat diakses oleh administrator jaringan dengan IP public dari server aplikasi. Administrator jaringan juga dapat mengakses aplikasi monitoring jaringan secara lokal apabila terhubung dalam jaringan lokal Al-Azhar BSD.

\subsection{Pengkodean Aplikasi}

Tahap ini adalah tahap dimana penulis melakukan pengkodean sistem setelah perancangan dilakukan, yaitu pengkodean aplikasi dan database. Penulis menggunakan bahasa pemograman PHP untuk aplikasi dan MySQL untuk database. Penulis menggunakan Codeigniter sebagai framework dalam pengkodean aplikasi, software PhpMyAdmin untuk database, dan Notepad++/gedit sebagai text editor.

\section{IMPLEMENTASI}

\subsection{Instalasi Aplikasi Pada Server}

Penulis melakukan instalasi aplikasi monitoring jaringan pada server proxy Al-Azhar BSD yang memiliki spesifikasi processor AMD Opteron Quad Core 2,35GHz, 8GB DDR3, OS Ubuntu Server 12.10, 4TB HDD. Proxy server Al-Azhar BSD menggunakan LAMPP dan memiliki alamat IP public 
sehingga memungkinkan aplikasi ini nantinya dapat diakses dari mana saja melalui browser.

\subsection{Instalasi Sistem-sistem Pendukung}

Pada tahap ini dilakukan instalasi dan konGambarurasi sistem-sistem pendukung agar aplikasi dapat berjalan dengan baik dan fitur-fitur aplikasi dapat berjalan sebagaimana mestinya. Sistem pendukung tersebut adalah:

1. Gammu, diperlukan sebagai perantara antara aplikasi dengan SMS Gateway untuk mengirimkan notifikasi SMS keadaan jaringan kepada administrator jaringan.

2. PHPSysInfo, diperlukan untuk membaca dan mengirimkan kepada aplikasi keadaan penggunaan resource dari server yang ada di Al-Azhar BSD

\subsection{Penginputan Data Device Jaringan}

Setelah aplikasi, database, dan sistem-sistem pendukung berjalan dengan baik, maka selanjutnya penulis melakukan penginputan data device-device jaringan yang penulis dapatkan pada tahap perencanaan syarat-syarat ke dalam database aplikasi. Penulis melakukan penginputan data melalui sistem inventori pada menu inventori pada aplikasi yang telah penulis buat.

\subsection{Pengujian Aplikasi}

Tabel 6.1 Pengujian Aplikasi

\begin{tabular}{|c|c|c|c|}
\hline Item $\mathrm{Uji}$ & Kegiatan & $\begin{array}{l}\text { Hasil yang } \\
\text { diharapkan }\end{array}$ & Hasil \\
\hline Login & $\begin{array}{l}\text { Memasukan } \\
\text { username dan } \\
\text { password }\end{array}$ & $\begin{array}{l}\text { Dapat masuk ke } \\
\text { halaman utama } \\
\text { administrator. }\end{array}$ & Sesuai \\
\hline Logout & $\begin{array}{l}\text { Klik Button } \\
\text { Logout }\end{array}$ & $\begin{array}{l}\text { Mengakhiri Session } \\
\text { dan kembali ke } \\
\text { halaman autentikasi. }\end{array}$ & Sesuai \\
\hline $\begin{array}{l}\text { Halaman } \\
\text { Status Host }\end{array}$ & $\begin{array}{l}\text { Memilih menu } \\
\text { Status Host }\end{array}$ & $\begin{array}{l}\text { Dapat menampilkan } \\
\text { daftar status host } \\
\text { berikut nama host, } \\
\text { alamat IP, status } \\
\text { online atau offline, } \\
\text { serta button Status } \\
\text { dan Detail pada } \\
\text { masing-masing host. }\end{array}$ & Sesuai \\
\hline $\begin{array}{l}\text { Halaman } \\
\text { Status } \\
\text { Port/Service }\end{array}$ & $\begin{array}{l}\text { Klik button } \\
\text { Status }\end{array}$ & $\begin{array}{l}\text { Depat menampilkan } \\
\text { status service/port } \\
\text { HTTP, FTP, SSH, } \\
\text { SMTP, HTTPS, dan } \\
\text { Telnet dari Host } \\
\text { yang dipilih. }\end{array}$ & Sesuai \\
\hline $\begin{array}{l}\text { Halaman } \\
\text { Detail Host }\end{array}$ & $\begin{array}{l}\text { Klik button } \\
\text { Detail }\end{array}$ & $\begin{array}{l}\text { Dapat menampilkan } \\
\text { detail informasi dari } \\
\text { host yang dipilih } \\
\text { termasuk status } \\
\text { pemakaian CPU dan } \\
\text { memory (RAM). }\end{array}$ & Sesuai \\
\hline $\begin{array}{l}\text { Halaman } \\
\text { Log Device }\end{array}$ & $\begin{array}{l}\text { Klik button Log } \\
\text { Kondisi pada } \\
\text { Detail Host }\end{array}$ & $\begin{array}{l}\text { Dapat menampilkan } \\
\text { daftar log tanggal } \\
\text { dan waktu perubahan } \\
\text { kondisi host yang } \\
\text { dipilih }\end{array}$ & Sesuai \\
\hline $\begin{array}{l}\text { Halaman } \\
\text { Active } \\
\text { Request }\end{array}$ & $\begin{array}{l}\text { Memilih menu } \\
\text { Active Request }\end{array}$ & $\begin{array}{l}\text { Dapat menampilkan } \\
\text { active request yang } \\
\text { sedang berjalan } \\
\text { berikut alamat host }\end{array}$ & Sesuai \\
\hline
\end{tabular}

\begin{tabular}{|c|c|c|c|}
\hline & & $\begin{array}{l}\text { request berasal, URI } \\
\text { request, dan } \\
\text { kecepatan host. }\end{array}$ & \\
\hline $\begin{array}{l}\text { Halaman } \\
\text { Log }\end{array}$ & $\begin{array}{l}\text { Memilih menu } \\
\log \end{array}$ & $\begin{array}{l}\text { Dapat menampilkan } \\
\text { persentase aktif dari } \\
\text { masing-masing host }\end{array}$ & Sesuai \\
\hline $\begin{array}{l}\text { Halaman } \\
\text { Log } \\
\text { Perubahan } \\
\text { Kondisi } \\
\text { Host } \\
\end{array}$ & $\begin{array}{l}\text { Klik tautan pada } \\
\text { alamat IP } \\
\text { masing-masing } \\
\text { host }\end{array}$ & $\begin{array}{l}\text { Dapat menampilkan } \\
\text { daftar log tanggal } \\
\text { dan waktu perubahan } \\
\text { kondisi host yang } \\
\text { dipilih }\end{array}$ & Sesuai \\
\hline $\begin{array}{l}\text { Halaman } \\
\text { Inventori }\end{array}$ & $\begin{array}{l}\text { Memilih menu } \\
\text { Inventori }\end{array}$ & $\begin{array}{l}\text { Dapat menampilkan } \\
\text { daftar keseluruhan } \\
\text { device/perangkat/hos } \\
t\end{array}$ & Sesuai \\
\hline $\begin{array}{l}\text { Tambah } \\
\text { Perangkat } \\
\text { /Host }\end{array}$ & $\begin{array}{l}\text { Klik tautan } \\
\text { Tambah Data } \\
\text { Baru }\end{array}$ & $\begin{array}{l}\text { Menampilkan form } \\
\text { penambahan device } \\
\text { jaringan dan dapat } \\
\text { melakukan } \\
\text { penambahan data } \\
\text { device jaringan }\end{array}$ & Sesuai \\
\hline $\begin{array}{l}\text { Edit } \\
\text { Perangkat/H } \\
\text { ost }\end{array}$ & Klik tautan Edit & $\begin{array}{l}\text { Menampilkan form } \\
\text { pembaruan data } \\
\text { device jaringan dan } \\
\text { dapat melakukan } \\
\text { pembaruan data } \\
\text { device jaringan }\end{array}$ & Sesuai \\
\hline $\begin{array}{l}\text { Hapus } \\
\text { Perangkat } / H \\
\text { ost }\end{array}$ & $\begin{array}{l}\text { Checklist item } \\
\text { yang ingin } \\
\text { dihapus } \\
\text { kemudian klik } \\
\text { button Hapus } \\
\text { yang Terpilih } \\
\end{array}$ & $\begin{array}{l}\text { Item yang terpilih } \\
\text { untuk dihapus } \\
\text { terhapus dari daftar } \\
\text { device dan database }\end{array}$ & Sesuai \\
\hline $\begin{array}{l}\text { Halaman } \\
\text { SMS } \\
\text { Gateway }\end{array}$ & $\begin{array}{l}\text { Memilih menu } \\
\text { SMS }\end{array}$ & $\begin{array}{l}\text { Masuk ke halaman } \\
\text { SMS Gateway, } \\
\text { menampilkan status } \\
\text { SMS Gateway, daftar } \\
\text { nomor handphone. }\end{array}$ & Sesuai \\
\hline $\begin{array}{l}\text { KonGambar } \\
\text { urasi SMS } \\
\text { Gateway }\end{array}$ & $\begin{array}{l}\text { Klik button Ubah } \\
\text { pada Status SMS } \\
\text { Gateway }\end{array}$ & $\begin{array}{l}\text { Masuk ke halaman } \\
\text { konGambarurasi } \\
\text { SMS Gatewaydan } \\
\text { dapat mengaktifkan } \\
\text { atau menonaktifkan } \\
\text { notifikasi melalui } \\
\text { SMS Gateway } \\
\end{array}$ & Sesuai \\
\hline $\begin{array}{l}\text { Tambah } \\
\text { Nomor }\end{array}$ & $\begin{array}{l}\text { Klik button } \\
\text { Tambah Nomor }\end{array}$ & $\begin{array}{l}\text { Menampilkan form } \\
\text { penambahan data } \\
\text { nomor penerima } \\
\text { notifikasi SMS dan } \\
\text { dapat menambah } \\
\text { nomor tujuan SMS }\end{array}$ & Sesuai \\
\hline Edit Nomor & $\begin{array}{l}\text { Klik tautan Edit } \\
\text { pada daftar } \\
\text { nomor }\end{array}$ & $\begin{array}{l}\text { Menampilkan form } \\
\text { pembaruan data } \\
\text { nomor penerima } \\
\text { notifikasi SMS dan } \\
\text { dapat mengubah data } \\
\text { nomor tujuan SMS }\end{array}$ & Sesuai \\
\hline $\begin{array}{l}\text { Hapus } \\
\text { Nomor }\end{array}$ & $\begin{array}{l}\text { Checklist item } \\
\text { yang ingin } \\
\text { dihapus } \\
\text { kemudian klik } \\
\text { button Hapus } \\
\text { Tercentang } \\
\end{array}$ & $\begin{array}{l}\text { Item yang terpilih } \\
\text { untuk dihapus } \\
\text { terhapus dari daftar } \\
\text { nomor dan database }\end{array}$ & Sesuai \\
\hline $\begin{array}{l}\text { Halaman } \\
\text { Log } \\
\text { Notifikasi } \\
\text { SMS } \\
\end{array}$ & $\begin{array}{l}\text { Klik button Log } \\
\text { Notifikasi }\end{array}$ & $\begin{array}{l}\text { Menampilkan } \\
\text { keseluruhan daftar } \\
\text { notifikasi SMS yang } \\
\text { terkirim }\end{array}$ & Sesuai \\
\hline $\begin{array}{l}\text { Hapus Log } \\
\text { Notifikasi } \\
\text { SMS }\end{array}$ & $\begin{array}{l}\text { Checklist item } \\
\text { yang ingin } \\
\text { dihapus } \\
\text { kemudian klik }\end{array}$ & $\begin{array}{l}\text { Item yang terpilih } \\
\text { untuk dihapus } \\
\text { terhapus dari daftar } \\
\text { log notifikasi SMS }\end{array}$ & Sesuai \\
\hline
\end{tabular}




\begin{tabular}{|c|c|c|c|}
\hline & $\begin{array}{l}\text { button Hapus } \\
\text { Tercentang }\end{array}$ & dan database & \\
\hline $\begin{array}{l}\text { Halaman } \\
\text { Detail Log } \\
\text { Notifikasi } \\
\text { SMS }\end{array}$ & $\begin{array}{l}\text { Klik tautan } \\
\text { Detail pada } \\
\text { daftar notifikasi } \\
\text { SMS }\end{array}$ & $\begin{array}{l}\text { Menampilkan detail } \\
\text { tanggal, waktu, isi } \\
\text { pesan SMS, dan } \\
\text { device yang } \\
\text { bersangkutan }\end{array}$ & Sesuai \\
\hline $\begin{array}{l}\text { Halaman } \\
\text { User }\end{array}$ & $\begin{array}{l}\text { Memilih menu } \\
\text { User }\end{array}$ & $\begin{array}{l}\text { Masuk ke halaman } \\
\text { User, menampilkan } \\
\text { keseluruhan daftar } \\
\text { user berikut } \\
\text { tingkatan dan hak } \\
\text { aksesnya. }\end{array}$ & Sesuai \\
\hline $\begin{array}{l}\text { Tambah } \\
\text { User }\end{array}$ & $\begin{array}{l}\text { Klik tautan } \\
\text { Tambah User }\end{array}$ & $\begin{array}{l}\text { Menampilkan form } \\
\text { untuk menambahkan } \\
\text { user dan dapat } \\
\text { menambahkan user } \\
\text { berikut hak akses dan } \\
\text { tingkatannya }\end{array}$ & Sesuai \\
\hline Hapus User & $\begin{array}{l}\text { Checklist user } \\
\text { yang ingin } \\
\text { dihapus } \\
\text { kemudian klik } \\
\text { button Hapus } \\
\text { yang Terpilih }\end{array}$ & $\begin{array}{l}\text { User yang terpilih } \\
\text { untuk dihapus } \\
\text { terhapus dari daftar } \\
\text { user dan database }\end{array}$ & Sesuai \\
\hline Edit User & Klik tautan Edit & $\begin{array}{l}\text { Menampilkan form } \\
\text { untuk mengedit } \text { user } \\
\text { dan dapat mengubah } \\
\text { data } \text { user berikut hak } \\
\text { akses dan } \\
\text { tingkatannya }\end{array}$ & Sesuai \\
\hline $\begin{array}{l}\text { Notifikasi } \\
\text { SMS } \\
\text { up/down }\end{array}$ & $\begin{array}{l}\text { Memutus } \\
\text { koneksi/mematik } \\
\text { an salah satu host }\end{array}$ & $\begin{array}{l}\text { User menerima } \\
\text { notifikasi SMS } \\
\text { mengenai informasi } \\
\text { host yang down }\end{array}$ & Sesuai \\
\hline $\begin{array}{l}\text { Notifikasi } \\
\text { SMS reboot } \\
\text { host }\end{array}$ & $\begin{array}{l}\text { Melakukan } \\
\text { reboot pada host } \\
\text { melalui aplikasi }\end{array}$ & $\begin{array}{l}\text { User menerima } \\
\text { notifikasi SMS } \\
\text { mengenai host yang } \\
\text { direboot }\end{array}$ & Sesuai \\
\hline $\begin{array}{l}\text { Notifikasi } \\
\text { SMS restart } \\
\text { service }\end{array}$ & $\begin{array}{l}\text { Melakukan } \\
\text { restart service } \\
\text { pada host melalui } \\
\text { aplikasi }\end{array}$ & $\begin{array}{l}\text { User menerima } \\
\text { notifikasi SMS } \\
\text { mengenai host yang } \\
\text { direstart servicenya }\end{array}$ & Sesuai \\
\hline $\begin{array}{l}\text { Notifikasi } \\
\text { SMS } \\
\text { penggunaan } \\
\text { CPU dan } \\
\text { RAM }\end{array}$ & $\begin{array}{l}\text { Menaikkan } \\
\text { pemakaian } \\
\text { CPU/RAM } \\
\text { hingga } \\
\text { melampaui batas }\end{array}$ & $\begin{array}{l}\text { User menerima } \\
\text { notifikasi SMS } \\
\text { mengenai kelebihan } \\
\text { pemakaian } \\
\text { CPU/RAM }\end{array}$ & Sesuai \\
\hline
\end{tabular}

Berdasarkan hasil dari pengujian blackbox yang dijabarkan pada Tabel 6.1 maka dapat disimpulkan bahwa setiap modul pada aplikasi yang telah dibuat dapat berfungsi dengan baik sesuai dengan sistem yang telah dirancang sebelumnya.

\section{KESIMPULAN}

Berdasarkan penelitian yang telah dilakukan, penulis menarik kesimpulan sebagai berikut:

1. Aplikasi monitoring jaringan ini dapat membantu memudahkan administrator jaringan dalam pemantauan jaringan yang dikelolanya, maka untuk itu aplikasi ini dirancang mempunyai fungsi monitoring, pencatatan kondisi host, dan sistem notifikasi perubahan keadaan host melalui SMS. Untuk memudahkan akses monitoring dari mana saja, administrator jaringan dapat mengakses aplikasi melalui browser biasa maupun mobile browser karena aplikasi ini telah dirancang berbasis mobile web dengan framework jQuery Mobile.
2. Aplikasi monitoring jaringan berbasis mobile web ini memanfaatkan Gammu sebagai SMS gateway untuk mengirimkan notifikasi perubahan kondisi host melalui SMS. Melalui aplikasi yang penulis buat, administrator jaringan dapat mengatur aktif atau tidaknya pengiriman notifikasi melalui SMS gateway.

\section{SARAN}

Aplikasi yang dibangun masih memiliki beberapa kekurangan dan keterbatasan, oleh karena itu ada beberapa hal yang perlu dikembangkan agar menjadi lebih baik, yaitu:

1. Aplikasi ini belum mencakup penanganan masalah yang timbul, diharapkan penelitian selanjutnya dapat membuatkan sistem penanganan masalah pada jaringan.

2. Aplikasi ini dibuat berbasis mobile web dengan framwerok JQuery Mobile sehingga keunggulannya adalah dapat dijalankan melalui platform apapun yang memiliki browser yang mendukung javascript. Namun tentunya akan lebih baik jika selanjutnya dikembangkan aplikasi native untuk setiap platform agar kompatibilitas lebih optimal.

3. Penambahan fitur-fitur monitoring yang lebih beragam lagi mengingat aplikasi ini dikembangkan secara modular sehingga memudahkan untuk menambahkan modul-modul atau fitur baru pada aplikasi.

\section{DAFTAR PUSTAKA}

[1] Bungin, Burhan. 2009. Penelitian Kualitatif. Jakarta: Kencana Prenda Media Group.

[2] Catur L. , Azis \& Herlambang, Moch. Linto. 2008. Panduan Lengkap Menguasai Router Masa Depan Menggunakan Mikrotik Router OS. Yogyakarta: Andi.

[3] Jogiyanto H. 1999. Pengenalan Komputer: Dasar Ilmu Komputer, Pemrograman, Sistem Informasi dan Intelegensi Buatan. Yogyakarta: Andi.

[4] Johnson, Michael. 2011. Network Monitoring: What You Need to Know for IT Operations Management. Tebbo.

[5] Kendall, Kenneth, E., \& Kendall, Julie, E. 2003. Analisis dan Perancangan Sistem. Jakarta: Gramedia.

[6] Kendall, Kenneth, E., \& Kendall, Julie, E. 2008. System Analysis And Design. London: Pearson International Edition $7^{\text {th }}$ Edition.

[7] H, Rafiza, 2006. Panduan dan Referensi Kamus Fungsi PHP5 Untuk Membangun Database Berbasis Web. Jakarta: PT Elex Media Komputindo.

[8] Lastiawan, Deni. 2011, Perancangan Sistem Monitoring Jaringan Berbasis Web Menggunakan Codeiginiter. Jakarta: UIN Syarif Hidayatullah.

[9] Mulyono, Hasyim.2008. Buku Pintar Komputer. Jakarta: Kriya Pustaka Jakarta.

[10] Mulyanto, Agus. 2009. Sistem Informasi Konsep \& Aplikasi. Yogyakarta: Pustaka Pelajar.

[11] Nazir, Moh. 2005. Metode Penelitian. Bogor: Penerbit Ghalia Indonesia.

[12] Pressman, Roger S. 2002. Rekayasa Perangkat Lunak Pendekatan Praktis. Terjemahan CN Harnaningrum. Yogyakarta: ANDI.

[13] Rifaldi, Ade.2013. Aplikasi Pencarian Buku Berbasis Lokasi Pada Smartphone Android Dengan Fitur 
Pencarian Menggunakan Algoritma Levensthein Distance (Studi Kasus: Toko Buku Gramedia). Jakarta: UIN Syarif Hidayatullah

[14] Rizky, Soetam. 2011. Konsep Dasar Rekayasa Perangkat Lunak. Jakarta: PT. Prestasi Pusta Karaya.

[15] Sopandi, Dede.2010.Instalasi dan KonGambarurasi Jaringan Komputer. Bandung: Informatika Bandung.

[16] Subhansyah, Nendy. 2005. Perancangan Sistem Akademik Sekolah Berbasis Teknologi Mobile Web. Jakarta: UIN Syarif Hidayatullah.

[17] Sugiyono. 2009. Metode Penelitian Administrasi. Bandung: CV Alfabeta Sutanta, Edhy. 2005. Pengantar Teknologi Informasi. Yogyakarta: Graha Ilmu.

[18] Suteja, Bernard Renaldy dkk. 2005. Mudah dan Cepat Menguasai Pemrograman Web. Bandung: Informatika.

[19] Wahyudi, Bambang. 2008. Konsep Dasar Sistem Informasi dari Bit Sampai ke Database. Yogyakarta: Andi.

[20] Widodo, Pudjo Prabowo \& Heriawati. 2011. Menggunakan UML. Bandung: Informatika

[21] Zed, Mestika. 2004. Metode Penelitian Kepustakaan. Jakarta: Yayasan Obor Indonesia. 